\title{
Tubular Breast Carcinoma
}

National Cancer Institute

\section{Source}

National Cancer Institute. Tubular Breast Carcinoma. NCI Thesaurus. Code C9135.

An invasive adenocarcinoma of the breast with a favorable prognosis. It is composed of tubular structures lined by a single layer of epithelium. 